\title{
PREDICTORS OF ACADEMIC PERFORMANCE AMONG SECOND-YEAR NURSING STUDENTS AT A UNIVERSITY IN THE WESTERN CAPE
}

\author{
K. D. T. Mthimunye* \\ e-mail: kmthimunye@uwc.ac.za
}

\author{
F. M. Daniels* \\ e-mail: fdaniels@uwc.ac.za
}

\author{
A. Pedro* \\ e-mail: aspedro@uwc.ac.za \\ *School of Nursing \\ University of the Western Cape \\ Bellville, South Africa
}

\section{ABSTRACT}

Students with low grades in high school science related subjects as well as those that obtained low grades in their first year of study should be given the necessary support to avoid the risk of unsatisfactory academic performance. The performance of nursing students is a diverse topic that needs further investigation at more nursing institutions and at various levels of undergraduate programmes. This study describes the predictors of academic performance among second-year nursing students at a university in the Western Cape. A non-experimental quantitative research approach with a cross-sectional predictive design was carried out to determine the relationship between predictor variables and academic performance of second-year Bachelor of Nursing students $(n=226)$. A multiple-linear regression analysis was done to determine which variables best explains the variations in the students' academic performance. The study found that the cognitive variables had the strongest predictive power in association with academic performance in comparison to the demographic variable, besides race which rejected the null hypothesis.

Keywords: academic performance, attrition, linear regression, nursing students, performance, Student Administration System Integrated (SASI), throughput

\section{INTRODUCTION}

Higher education institutions (HEIs) offering Bachelor of Nursing (BN) programmes worldwide remain under tremendous pressure of graduating larger quantities of graduate nurses to meet the desired nursing labor-force (Bovbjerg, Ormond and Pindus 2009). In addition to this, South African HEIs are grappling with producing quality graduates within an increasingly 
competitive context (Harvey and Kamvounias 2008). Nursing students generally access a tertiary institution such as a university to obtain a BN programme. However, not all BN students will achieve the minimum requirements set to complete the programme to complete the programme. In many instances, academic performance is measured by continuous assessment and examination conducted in higher education. Personal communication in 2014 with experts in the field of teaching and learning, at a School of Nursing (SoN) in the Western Cape, confirmed that many nursing students encounter difficulties in their second year of study, which is evident from unsatisfactory performance and pass rates at this level of the programme. The SoN has a vision that is geared towards student excellence in both academic and clinical spheres. Predicting academic performance and distinguishing factors that place BN students in danger of unsatisfactory academic performance are therefore critical issues for nurse educators to address.

Meyer and Van Niekerk (2008) emphasised that excellent performance forms the integral foundation of quality assurance and maintenance of high standards with specific reference to the requirements of the South African Education and Training Quality Assurance Body (ETQA). Careful recruitment of students who exhibit potential for excellent academic and clinical performance is imperative. Like any other programme within the faculty of Community and Health Sciences (CHS) at the identified HEI in the Western Cape, there are a set of schoolleaving requirements that allows applicants access to the BN programme. However, there is lack of published studies that examine whether or not these academic requirements are significant predictors of performance and success in the second-year of the BN programme. The situation is exacerbated by the recent introduction of National Senior Certificate (NSC) as certified by the ETQA (Umalusi) in 2008. The NSC is the certificate awarded as the final exit qualification at the end of Grade 12 (NSC 2013). The NSC replaced the Senior Certificate (SC) as the major school-leaving qualification. For the NSC, all subjects are now offered at a single level which was found generally to be the midway between the standard grade and the highergrade levels associated with the SC (NSC 2013). As a result of these changes the quality of the students that are admitted in the BN programme has changed significantly which warranted further research on the predictors of academic performance among second-year nursing students.

\section{LITERATURE}

Previous studies have focused on the factors that influence academic performance success and retention of undergraduate nursing students in the course of recent decades (Jeffreys 1998; 
2002; 2007; Manifold and Rambur 2001; Shelton 2003). In spite of that, findings have not been conclusive on which factor or combination of factors has had the greatest predictive influence on nursing students' academic performance. The obvious lack of research on the predictors of academic performance supports the need for further studies to be conducted. The Nursing Undergraduate Retention and Success (NURS) model by Jeffreys (2013) indicates that the academic performance and eventually the retention of undergraduate nursing students is based on the interaction of student profile characteristics, student affective factors, academic factors, environmental factors, academic outcomes, psychological outcomes, outside surrounding factors, and professional integration factors. Therefore, various combinations of these factors may provide the researchers with significant evidence that may be vital in identifying variables that have the greatest predictive power on the academic performance and success of nursing students. While acknowledging that there are multiple intrinsic and extrinsic factors that predict student retention and success, the next section discusses only the predictor variables that are of interest to the study.

\section{Demographic predictors}

Age, gender and ethnicity have been revealed to be the most statistically significant indicators of academic performance among nursing students (Wong and Wong 1999; Salamonson and Andrew 2006; Meadus and Twomey 2007).

\section{Age}

The cognitive theorist Malcolm Knowles (1970) in his assumptions describes adult learners as experienced beings, self-directed, ready-to-learn-students; these characteristics may contribute towards adult learners’ academic performance (Cercone and Kathleen 2008).

Further studies Salamonson and Andrew (2006) have shown that older students academically outperformed their younger counterparts. This finding may be linked to the fact that older students are self-directed and display a high level of self-motivation. Goddard, Mannion and Smith (2004) reported that older nursing students perform better in their nursing studies regardless of their previous qualifications, whilst younger students with better academic background perform unsatisfactorily. El Ansari (2002) found that students between the ages of 26 and 50 years performed better in their examinations than those below the age of 26 years. This may be because adult students have accumulated a large amount of life experience and sense of maturity. However, Steele et al. (2005) reported that older students go through problems, such as financial constraints and psychosocial stressors, which may affect their 
academic performance; these may serve as a motivation and encourage these students to perform well.

\section{Gender}

Like age, the impact of gender was a factor that was considered by many researchers. Various studies have been conducted evaluating the effect of student gender on performance, and it was found that there were no substantial variations between male and female students regarding academic performance (Meadus and Twomey 2007). However, one has to bear in mind that traditionally the nursing profession has been predominantly a female profession. Female nurses have a caring nature inherent in nursing, and this is associated with the female role (Ehrenreich and English 2010). Meadus and Twomey (2007) detailed that male applicants were prevented from taking nursing as a profession, owing to the perceptions of the community, the value of nursing to society and sexual stereotypes. Males are seen as a nursing minority, which might negatively affect their performance. The profession has grown enormously, and more men are being recruited into the profession (Wise 2009).

\section{Ethnicity}

Like age and gender, ethnicity has been revealed to be one of the statistically significant demographic indicators of academic performance amongst nursing students (Wong and Wong 1999; Lewis and Lewis 2000; Beeson and Kissling 2001). A study by Rule (2004) reported a high percentage of success among BN White $(n=309)$ than African-American $(n=32)$ students. Higgins (2005) reported a statistically insignificant relationship between nursing students' ethnicity and success in undergraduate nursing programmes. However, these findings may not necessarily apply at UA owing to the level of ethnic and racial diversity in South Africa.

Over the years, the profile of students registering for nursing programmes has changed, particularly in South Africa post-apartheid. More and more previously disadvantaged ethnic groups such as Black and Coloured students are admitted at HEIs (Chisholm and Bhorat 2004). Such changes allow new research to be undertaken to re-evaluate the predictive power of ethnicity on the academic performance of second-year nursing students at the university identified for this study.

\section{Cognitive predictors}

\section{Admission points}

The South African NSC is awarded to students who have complied with the specific requirements (as published by Umalusi - the Council for Quality Assurance in General and 
Further Education and Training). These requirements form the basis for determining whether the student can be accepted at any of the HEIs for the higher certificate, diploma or degree programme.

To qualify for entrance in to a bachelor's degree programme at a HEI, the student must pass with at least 30 per cent in the language of teaching and learning of the HEI concerned. Furthermore, the student will be required to obtain a minimum achievement of 50-59 per cent or higher in four subjects chosen from the designated subject list decided by the HEI (NSC 2013).

Admission points are vital in assisting students with the move from high school to HE. Traditionally it would be profoundly likely that students who performed better in their final year of high school would outperform those who did not do well (Hopkins 2008). This assertion may be based on the premise that students who have scored high grades for grade 12 have inherent advanced cognitive abilities or levels of intelligence and/or are hard working. One would stereotypically anticipate these dimensions to extend to tertiary level. Hopkins (2008) argued that the high school average grade, the Scholastic Aptitude Tests (SAT) and the reasoning test were educators of academic performance.

\section{High school science and mathematics grade}

It would be reasonable to anticipate that students who scored high grades in the Grade 12 science and mathematics subjects will perform better than those students with lower grades or those with no science or mathematics background. This assumption stems from the fact that nursing also forms part of science and therefore the relationship between high school science subjects and nursing science is of high correlation. Regulation 425 of the Nursing Act 33 of 2005, as amended, stipulates that general nursing science (GNS) ought to be an obligatory module in nursing education and should form the basis of nursing science which requires an understanding of human biology, physical science, chemistry and pharmacology. This articulation infers that mathematics, physical science, life science and life orientation are strongly recommended high school subjects for understanding the foundation of nursing and for success in general nursing science. However, there is minimal confirmation on whether high school science and mathematics subjects expand the probability of success among nursing studies.

\section{National Benchmark Test}

In 2005, Higher Education South Africa (HESA) assigned the National Benchmark Tests (NBT) to substitute the Alternative Admissions Research Project (AARP) which as of 2012 is 
no longer used. The NBT is an assessment for students wishing to be admitted into HEIs. Data proportional to the predictor variables of mathematics skills, science background and students' responses on standardized nursing aptitude assessments are tested by the NBT. The tests are used by many tertiary institutions including the SoN at UA as an admission screening tool. The NBT was outlined to assess the student's ability to transfer understanding of academic literacy, quantitative literacy and mathematics to the demands of tertiary coursework. The test outcomes provide the HEIs with critical evidence about the scholarly competence of students on entry to HEI. NBT likewise provides HEIs with data to help with the placement of new students in appropriate programmes (e.g. regular or foundation programmes). The main purpose of the NBT is not to replicate the same evidence as that acquired from the final year high school examination but to assess students' verbal reasoning, quantitative and mathematics literacy (Griesel 2006).

Two tests (academic and quantitative literacy and mathematics) are designed to facilitate the placement of first-year students into the extended nursing or mainstream programmes at the SoN. These tests were first conducted in 2009, and it is therefore too early to determine their predictive capacity regarding students' academic performance. Therefore, research to determine the predictive value of the NBTs regarding nursing students' academic performance at the second-year level is therefore valuable.

\section{Aggregate results in first year}

There is a great level of integration between various levels in the BN programme; this implies that the curriculum being taught in second year would build on the knowledge gained in the first year of study. This practice is referred to as vertical articulation by the National Qualification Framework (NQF). One would strongly anticipate that a student's aggregate result in the first year of study would be indicative of their performance in their second year of study. However, Mouton, Louw and Strydom (2012) argued that the quality of secondary education level has a direct implication on the performance of students at university level, with many learners subsequently underperforming due to lack of preparedness at school level.

Student's performance in the second year of the four-year BN programme was the focus of this research study. Performance is addressed in two categories: performance in second-year nursing modules (General Nursing Science (NRS211) and General Nursing Science (NRS212)) and performance in science modules (Human Biology (HUB218), Human Biology (HUB 228) and Pharmacology (PHA)). 


\section{RESEARCH DESIGN AND METHOD}

A non-experimental quantitative research approach with a cross-sectional predictive design was employed to determine the link between predictor variables and academic performance of second-year BN students at a SoN. Two hypotheses were formulated: H1: Students' age, gender, and ethnicity are significant predictors of academic performance of second-year nursing students and H2: Student's grades (admission points, grades in science and mathematics, NBT grade, first year average grade) are significant predictors of academic performance of secondyear nursing students.

All-inclusive sampling was employed. The total sample for the present study, consisted of the sum of the sample obtained from a group of nursing students who were registered for second-year in $2012\left(n_{1}=101\right)$ and in $2013\left(n_{2}=125\right)$. The selected sample $(n=226)$ included all nursing students registered in 2012 and 2013 for BN second year at the SoN identified for the study. The inclusion criteria set for the present research study were to include only those students who obtained a NSC as certified by Umalusi and attempted the second year of BN programme for the first time in the year 2012-2013.

\section{DATA COLLECTION}

The present study involved of the collection of data from a student information system belonging to the university also known as the Student Administrative System Intergraded (SASI). Admission and academic records of nursing students registered for their second year BN programme from 2012 to 2013 provided the main source of data for the study. The applicable information was obtained from the original documentation of students (for example, official academic records) by the faculty administration officers. The SASI database incorporates information signifying student profile characteristics for example demographics, high school subjects and grades, earned degrees, grades in post high school courses, NBT grade, and grades in nursing courses. The following variables were requested from SASI: demographic variables (age, gender, ethnicity), cognitive predictors (second-year grade for science modules, second-year grade for nursing modules, National Benchmark Test, high school life orientation grade, high school life science grade, high school physical science grade, high school mathematics grade, admission point, first-year grade for nursing modules, first-year grade for science modules) and non-cognitive predictors (place of residence and home language).

The above data for these variables were obtained to empower the researcher to test the hypothesis set for the present study. The researcher, with the support from the research associate, extracted the required data from the SASI database. As a means of ensuring that the 
data was accurately extracted, the data collected was recorded onto a Microsoft Excel spreadsheet.

\section{DATA ANALYSIS}

Descriptive and inferential statistics were utilised to analyse obtained data by means of the IBM Statistical Package for Social Sciences (IBM SPSS-23). Descriptive statistics was used to provide statistical summaries of the data. Inferential statistics was used to obtain more complex statistical analysis such as correlational analysis which determined the correlation among study variables. Simple and multiple regression analysis were performed to test the hypotheses and to establish the predictive power of the predictor variables in predicting the performance of second-year nursing students. Analysis of Variance (ANOVA) was utilised to test the relationship between gender (male and female), ethnicity (White, Black, Coloured and Indian) ${ }^{1}$ and academic performance of students in their second-year of study.

\section{RIGOR}

A statistician and the study overseer were consulted to affirm the suitability and the precision of the data collection tool. A pre-test of the data collection tool was conducted to test the feasibility of the checklist used to collect data from SASI to establish the inter-rater reliability. Content validity of the instrument was grounded on the NURS framework which pronounce that the interaction between personal, academic and environmental variables have an impact on the academic success among undergraduate nursing students (Jeffreys 2015).

\section{RESEARCH ETHICS}

Endorsement to conduct this study was permitted by the research ethics committee of the university identified for the study (Registration No. 14/9/38). The university Registrar as well as the head of the SoN granted authorization for the study to be carried out. The researcher kept up the code of anonymity and privacy throughout the study.

\section{RESULTS AND DISCUSSION}

\section{Second-year nursing grade}

The nursing modules included were NRS211, NRS212 and CUR214. The grades ranged from 48.5 per cent to 90 per cent with a mode of 65 per cent and a median of 65 per cent. The mean grade was 65.6 per cent with a standard deviation (SD) of 8.2. 


\section{Second-year science grade}

The science modules included were HUB218, HUB228 and PHA204. For this study, the second-year science grade ranged from 29 per cent to 87.67 per cent with a mode of 50 per cent and a median of 58.5 per cent. The mean grade was found to be 53.41 per cent $(S D=10.61)$. It is difficult to compare academic performance with that found by other researchers, as researchers in other studies have implemented various scales and variables to measure performance.

\section{Multiple regression analysis}

\section{Models for second-year nursing grade}

Model 1: Executes a standard multiple regression analysis between student performances in second-year nursing modules as the dependent variable and demographic predictor variables. Therefore, the variables included in this model were age, gender and ethnicity. This model attempts to pinpoint the variables, for which information is accessible before the student commence with the BN programme, that have an impact on the student's academic performance in the second-year modules. The adjusted $\mathrm{R}^{2}$ of 0.160 relating to model 1 is lower than the $\mathrm{R}^{2}$ of model 2 (0.538) and model 3 (0.520).

Model 2: Executes a standard multiple regression analysis between student performances in second-year nursing modules as the dependent variable and cognitive predictor variables. Therefore, the variables included were life sciences grade, physical sciences grade, mathematics grade, life orientation grade, admission points, first-year nursing grade and first-year science grade. This model attempts to identify the cognitive predictors that affect the student's performance in the second-year nursing modules. The adjusted $\mathrm{R}^{2}$ of 0.538 relating to model 2 is high than the $\mathrm{R}^{2}$ value of model $1(0.160)$. A possible conclusion that can be drawn is that significant development occurs when considering the cognitive background of the students.

Model 3: Executes a standard multiple regression analysis including all study variables relating to demographic and cognitive factors distinguished in the main model above as the significant predictor variables and second-year nursing modules as a dependent variable. Second-year nursing grade as continuous dependent variable was operationalised by taking the average grade for nursing modules that are prescribed for second-year BN students. Of the 226 sample, 225 (99.56\%) participants were included and only 1 (0.44\%) student was excluded owing to the missing score. For this model, the generalised $\mathrm{R}^{2}$ was 0.604 and the adjusted $\mathrm{R}^{2}$ 
was 0.520 , which indicates that the all-inclusive set of predictor variables explained approximately 52 per cent to 60.4 per cent of the variation in student performance for nursing modules. The variables found to be significant $(p<0.01)$ for this dependent variable (according to rank) are first-year science grade (0.679), first-year nursing grade (0.677), mathematics grade (0.437), admission points (0.437) and NBT (0.383).

A stepwise regression for second-year nursing grade (dependent variables) was performed to establish the combination of variables that provide the highest adjusted $\mathrm{R}^{2}$ and report the results under model 4.

Model 4: A stepwise regression for nursing modules revealed that first-year science grade $(\beta=0.345 ; p<0.01)$, first-year nursing grade $(\beta=0.394 ; p=0.001)$ and NBT $(\beta=0.187 ; p$ $<0.10$ ) grade are significant predictors of second-year nursing modules whereas the rest of the predictor variables were excluded. The $\mathrm{R}^{2}$ for this model was found to be 0.573 which is significantly higher than the $\mathrm{R}^{2}$ value for the above models. These differences in $\mathrm{R}^{2}$ implies that module 4 (0.573) explains more variations in second-year nursing modules than model $1\left(\mathrm{R}^{2}=\right.$ $160)$, model $2\left(\mathrm{R}^{2}=538\right)$ and model $3\left(\mathrm{R}^{2}=520\right)$ and therefore suggest that first-year nursing grade, first-year science grade and NBT have more significant predictive power than other variables (admission points, high grades in science subjects and mathematics) included in the present study. Table 1 summarises the results of stepwise regression for second-year nursing modules.

Table 1: Coefficients dependent variable: Second-year nursing modules grade

\begin{tabular}{|c|c|c|c|c|c|c|}
\hline \multirow{2}{*}{ Model } & & \multicolumn{2}{|c|}{$\begin{array}{c}\text { Unstandardised } \\
\text { coefficients }\end{array}$} & \multirow{2}{*}{$\begin{array}{c}\text { Standardised } \\
\text { coefficients } \\
\text { Beta } \\
\end{array}$} & \multirow{2}{*}{$T$} & \multirow{2}{*}{ Significance } \\
\hline & & B & $\begin{array}{l}\text { Standard } \\
\text { error }\end{array}$ & & & \\
\hline \multirow[t]{2}{*}{1} & (Constant) & 26.385 & 5.441 & & 4.849 & .000 \\
\hline & First-year science grade & .606 & .083 & .679 & 7.285 & .000 \\
\hline \multirow[t]{3}{*}{2} & (Constant) & 9.956 & 7.138 & & 1.395 & .168 \\
\hline & First-year science grade & .359 & .108 & .402 & 3.310 & .002 \\
\hline & First-year nursing grade & .456 & .140 & .396 & 3.264 & .002 \\
\hline \multirow[t]{4}{*}{3} & (Constant) & 7.223 & 7.068 & & 1.022 & .311 \\
\hline & First-year science grade & .308 & .108 & .345 & 2.843 & .006 \\
\hline & First-year nursing grade & .454 & .136 & .394 & 3.338 & .001 \\
\hline & NBT & .142 & .068 & .187 & 2.099 & .040 \\
\hline
\end{tabular}

\section{Models for second-year science grade}

Model 1: Executes a standard multiple regression analysis between student performances in second-year science modules as the dependent variable and demographic predictor variables. Therefore, the variables included in this model were age, gender and ethnicity. This model 
endeavors to distinguish the study variables for which data is available at the time prior to the student admission in to the BN programme, that influence the student's academic performance in the second-year modules. The adjusted $\mathrm{R}^{2}$ of 0.120 relating to model 1 is lower than the $\mathrm{R}^{2}$ of model 2 (0.569) and of model 3 (0.548).

Model 2: Execute a standard multiple regression analysis between student performances in second-year science modules as the dependent variable and cognitive predictor variables. Therefore, the variables included were life sciences grade, physical sciences grade, mathematics grade, life orientation grade, admission points, first-year nursing grade and first-year science grade. As for model 2 of the second-year nursing models, this regression was designed to provide evidence of the predictive power of cognitive predictors known by the end of the first year on second-year science modules. The adjusted $\mathrm{R}^{2}$ of 0.569 relating to model 2 is higher than that of model $1(0.120)$. Model 2 provides the significance of cognitive predictive variables in predicting academic performance in second-year science modules.

Model 3: Executes a standard multiple regression analysis including all study variables relating to demographic and cognitive factors established in the key models above as the predictor variables and second-year science modules as the dependent variable. This continuous dependent variable was operationalised by using the average grade for science modules that are prescribed for second-year BN students. Of the 226 (98.23\%) participants, 222 (1.77\%) were included and 4 were excluded owing to missing scores. For this model, the generalised $\mathrm{R}^{2}$ was 0.627 and the adjusted $\mathrm{R}^{2}$ was 0.548 , demonstrating that the total set of predictor variables explain about 54.8 per cent to 62.7 per cent of the variability in student performance. The variables that were found to be significant $(p<0.01)$ for this dependent variable (according to rank) were first-year science grade (0.765), first-year nursing grade (0.627), physical science (0.448), admission points (0.428), maths (0.419), life science (0.418) and NBT (0.358).

A stepwise regression for second-year science grade (dependent variables) was performed to establish the combination of variables that provide the highest adjusted $\mathrm{R}^{2}$ and report the results under model 4.

Model 4: A stepwise regression was performed on this model with second-year science grade as the dependent variable. All predictor variables were included in the regression to establish the combination of variables that best predict performance in second-year science modules. All predictor variables were excluded in this model except first-year science modules ( $\beta=0.765 ; p<0.001)$ which was found to be highly significant in this model with $\mathrm{R}^{2}$ of $(0.585)$. The $\mathrm{R}^{2}$ in this model is higher than the $\mathrm{R}^{2}$ in model 4 (0.540). This implies that model 4 explains more variations than model $1\left(\mathrm{R}^{2}=120\right)$, model $2\left(\mathrm{R}^{2}=569\right)$ and model $3\left(\mathrm{R}^{2}=548\right)$. The 
higher $\mathrm{R}^{2}$ (Model 4; 0.585) indicates that first-year science modules have more predictive power than other variables included in the study. Table 2 summarises the results of stepwise regression for second-year nursing modules.

Table 2: Coefficients dependent variable: Second-year science modules grade

\begin{tabular}{|c|l|c|c|c|c|c|}
\hline \multirow{2}{*}{ Model } & & \multicolumn{2}{|c|}{$\begin{array}{c}\text { Unstandardised } \\
\text { coefficients }\end{array}$} & $\begin{array}{c}\text { Standardised } \\
\text { coefficients }\end{array}$ & \multirow{2}{*}{ T } & Significance \\
\cline { 3 - 7 } & & B & Std. Error & Beta & & .551 \\
\hline \multirow{2}{*}{1} & (Constant) & -3.703 & 6.173 & & -.600 & .000 \\
\cline { 2 - 7 } & First-year science grade & .882 & .094 & .765 & 9.344 & .000 \\
\hline
\end{tabular}

\section{Significant predictor variables}

The two predictors of good academic performance identified in this study (first-year science and first-year nursing grade) reflect the student's characteristics post admission to the BN programme. This implies that significant impact in the students' academic performance occurs when the student constructs his or her own knowledge. Generally, the environment in HEI's is structured to promote teaching and learning. This includes accessibility to teaching and learning resources (library, computer laboratory, and educators etc.). The significant predictor variables identified in this study can be understood within the context of the theory of constructivism as it applies to all aspects of teaching and learning (Biggs 2011). Constructivism asserts that individuals construct meaning and knowledge of the world when they experience things and reflect on those experiences. When an individual encounter something new they either reconcile it with previously learnt ideas and experiences or they discard the new information as irrelevant (Shukla and Yadav 2011).

Another theoretical underpinning to the findings of this study is cognitive development theory which emphasises the role of mediation within the process of learning (Vygotsky 1978). Vygotsky perceived learning as a process taking place between a learner and a more advanced peer or adult instructor (Crain 2015). This is known as the 'zone of proximal development' which refers to the difference between what a student can do independently and the student will be able to accomplish with the help a more knowledgeable person (Chaiklin 2003). It is essential therefore that nurse educators create a learning environment that allows for optimal cognitive development in nursing students with their support. Vygotsky (1978) also highlighted the role of social context in the construction of meaning and learning (Jarvis 2012) and emphasised that individuals can develop a quicker and more advanced understanding during interaction with other people such as adults or more experienced peers. Therefore, learning opportunities in sufficient amount, quality and relevance to the programme in addition to the necessary support 
should be planned and secured to allow meaningful interaction about the theory and practice of nursing among students and educators.

In line with this thinking, nurse educators at the school of nursing are responsible for facilitating students' development of critical thinking, sound clinical judgment and reflective practice. For this to occur, the educator ensures that the learning environments where both theory and clinical learning occur are conducive to support meaningful learning. The structure of the BN programme is deliberate in ensuring scaffolding of learning in a way that new knowledge is underpinned by existing knowledge and that deep learning occurs when learning is facilitated and supported through the development of student's meta-cognition.

In this study the following variables were found to be significant predictors of academic performance among second-year nursing students at the selected SoN.

\section{First-year science grade}

The value of previous science achievements as a predictor of performance of nursing students has been validated in previous studies (Brennan, Best and Small 1996; Potolsky, Cohen, and Saylor 2003; Newton, Smith, Moore and Magnan, 2007). In the present study, student achievements in first-year science modules were found to have a significant impact on both second-year nursing grade and second-year science grade. Similar to the findings of Callister et al. (2005) and Potolsky et al. (2003) students' performance in previous science modules has a significant $(p=0.01)$ relationship with nursing student academic performance. The first-year science grade was calculated from student grades in Human Biology 118 (HUB118), Human Biology 128 (HUB128), Physics for CHS (PHY118) and Chemistry 128 (CHM128). The mean score for first-year science grade was 64.7 per cent $(S D=9.2)$. The Pearson $r$ correlation results revealed a high significant $(0.765, p<0.01)$ relationship between first-year science modules and second-year nursing modules. Furthermore, a high significant $(0.679 ; p<0.01)$ relationship was observed between first-year science modules and second-year science modules. In a stepwise regression (model 4) that was performed with second-year science grade as a dependent variable, all predictor variables were excluded in this model except first-year science modules ( $\beta=0.765 ; p<0.001)$ which was found to be highly significant in this model with $\mathrm{R}^{2}$ of $(0.585)$. A stepwise regression for nursing modules revealed that first-year science grade is one of the three predictor variables found to be significant $(\beta=0.345 ; p<0.10)$ in predicting the average nursing grade for students attempting their second year of the BN programme at UA. It therefore appears that first-year grade in science modules proves to be a reliable predictor of student performance in both second-year nursing and science modules. 


\section{First-year nursing grade}

In the present study, first-year nursing grade was found to be one of the significant ( $\beta=0.394$; $p=0.001)$ predictors of performance in second-year nursing modules. This significance can be explained by the anticipated interrelationships between the year levels of the BN programme. The first-year nursing grade was calculated from Fundamentals of Nursing Science (NUR112), Fundamentals of Nursing Science (NUR111), and Clinical Nursing (CUR111). The first-year nursing grade ranged from 52.67 per cent to 93.33 per cent with a mode of 73 per cent and median of 71 per cent. The mean of 71.14 per cent was calculated with a SD of 7.13. The Pearson $r$ correlation results revealed a high significant $(0.677, p<0.01)$ correlation between first-year nursing modules and second-year science modules. In a stepwise regression (model 4) that was performed with second-year nursing grade as a dependent variable, first-year nursing grade was one of the three predictor variables that was found to be significant $(\beta=$ 0.394; $p=0.001 ; \mathrm{R}^{2}=0.573$ ) in predicting academic performance of second-year nursing students in nursing modules. Therefore, first-year grade in nursing modules proves to be a reliable predictor of student performance in second-year nursing modules.

\section{National Benchmark Test grade}

According to previous studies, the value of university entrance tests was reported to have a significant impact on the academic performance of nursing students (Simmons, Haupt and Davis 2004; Symes, Tart and Travis 2005; Alden 2008). The grade of the NBT, which was administered to students prior to entering the BN programme, was calculated from student scores in Academic Literacy (AL), Quantitative Literacy (QL) and Mathematics. The NBT grade for 122 (53.98\%) students were missing. Analysis of this variable was performed on the total number of participants ( $n=144 ; 46.02 \%$ ) who were requested to complete the tests. The NBT grade ranged between 28.33 per cent and 65 per cent with a mode of 42.33 per cent and median of 41.75 per cent. The mean was also calculated and found to be 43.40 per cent with SD of 8.38. The Pearson $r$ correlation results revealed a moderately significant $(0.383 ; p<0.01)$ relationship between NBT grade and grade in second-year nursing modules. The Pearson $r$ correlation between NBT and other significant variables (first-year science grade and first-year nursing grade) was also analysed. The correlation between NBT grade and first-year science grade showed that there is a moderate correlation $(0.224 ; p<0.10)$ between the two. Similarly, the Pearson $r$ correlation between NBT grade and second-year science grade revealed a moderate correlation $(0.313 ; p<0.01)$ between the two. A stepwise regression for nursing 
modules revealed that NBT grade is one of the three predictor variables found to be significant $(\beta=0.187 ; p<0.10)$ predictors of academic performance in second-year nursing models. However, it was found to be non-significant in predicting the performance in second-year science grade.

Although this study identified cognitive variables as significant predictors of academic performance, success and throughput among second-year nursing students, non-cognitive predictors, which were not tested in this study, may yield certain predictive powers if tested. Such non-cognitive predictors may contribute significantly towards the success of second-year nursing students.

\section{Non-significant predictor variables}

\section{Age}

At the time of admission to the BN programme, the youngest student was 17 years old whilst the oldest was 30 years of age. The mean age of the students was 19.5 years (SD = 1.4); the median age was 19 years. Age was not a significant predictor variable for performance in second-year nursing and science modules. The researcher, however, believes that it would have been significant if the sample were larger. The lack of significance is probably because the researcher was interested in students with NSC, which was only implemented in 2008, and therefore this resulted in the sample being focused around and very close to the mean age. Previous studies about performance of nursing students have reported inconsistent results. Wong and Wong (1999) reported that older students were more likely to outperform their younger counterparts. They found that age was a significant predictor of academic performance and success of nursing students. Alden (2008) found in her study that age is not a significant predictor of nursing student performance. These findings imply that more research should be conducted with much larger sample sizes to verify the significance of age in predicting student performance. Malcolm Knowles (1970) best known for his adult learning theory defined andragogy as the art and science of helping adults to learn (Gravett 2005). Knowles' theory suggests that as an individual matures his/her self-concept moves from dependent towards one of self-directed learning; that adults accumulates experiences; that adult's approach to learning is more problem-centered than subject-centered and that adults are motivated to learn by external factors. Based on this andragogic learning theory by Knowles, it is highly likely that the older BN students would outperform their younger counterparts. The tenets of Knowles 
theory are also espoused and evident in the BN nursing programme which adopts a studentcentred, case-based approach to teaching and learning.

\section{Gender}

Of the selected sample ( $n=226)$ in the study, the majority were female $(n=188,83.19 \%)$ and the minority were male $(n=38,16.81 \%)$. One-way ANOVAs were used to test for differences in mean performance (second-year science and nursing performance) for defined male and female students.

\section{Variances between gender and second year nursing grade}

No statistical relationship was identified between gender and second year grade in nursing modules. Kruskal-Wallis ( $p>0.05)$ one-way ANOVA accepted the null hypothesis for this variable and all medians were found to be equal

\section{Variance between gender and second-year science grade}

No statistical relationship was identified between gender and second-year grade in science modules. Kruskal-Wallis ( $p>0.05)$ one-way ANOVA accepted the null hypothesis for this variable and all medians were found to be equal.

The results of the regression and the ANOVA indicated that there was no significant relationship between gender and performance of nursing students in both the nursing and science modules. However, the researcher believes that if the sample had been more diverse, different findings would have presented. Previous studies by Dyck et al. (2009) and McLaughlin, Muldoon and Moutray (2010) reported that academic performance of male students exceeds that of their female counterparts. No evidence was found of studies reporting the significance of gender on the performance of second-year nursing students on nursing modules as well as science modules.

\section{Ethnicity}

Previous studies found that ethnicity plays an important role in predicting nursing student performance (Barbee and Gibson 2001; Gardner 2005). These studies revealed that the minority group is likely to encounter more barriers to their success and performance in nursing studies. However, in the present study, different results were obtained. The study sample was predominantly black students who comprised 53.10 per cent $(n=120)$ of the study participants. The second-largest group consisted of coloured students who made up 35.40 per cent $(n=80)$ of 
the participants. The minority ethnical groups in the study included White students $(n=23$; $10.18 \%$ ), followed by Indian students ( $n=2 ; 0.88 \%)$ and other ethnic groups amounted to one $(n=1 ; 0.44 \%)$. In the present study, ethnicity was found to be a statistically non-significant predictor of nursing student performance during the stepwise regression analysis.

Although ethnicity was found to be an insignificant predictor of performance in secondyear nursing and science modules grade, the ANOVA results revealed different results. Additional one-way ANOVA was performed and, interestingly, the analysis rejected the null hypothesis (Table 3 and Table 4). These results imply the acceptance of the hypothesis which indicates that ethnicity is a significant predictor of academic performance by second-year nursing students in both nursing and science modules. The findings revealed unexpected findings that the minority ethnical groups outperformed their majority counterpart. However, given the history of the country, White student were more privileged and more advantaged regarding their schooling and the way they were raised. This influence could contribute considerably towards the outcome of student success and performance. In contrast, Black students were less privileged and in many cases attended under-resourced schools. The context has not changed much as the majority of Black students still come from low-income and underresourced communities, bearing in mind the university’s mission to serve the less privileged.

Table 3: Kruskal-Wallis test results (ethnicity and second-year nursing grades)

\begin{tabular}{|l|c|c|c|c|}
\hline \multicolumn{1}{|c|}{ Method } & $\begin{array}{c}\text { Degree of } \\
\text { Freedom (DF) }\end{array}$ & Chi-square & Probability level & $\begin{array}{c}\text { Decision } \\
(\mathbf{0 . 0 5})\end{array}$ \\
\hline Not corrected for ties & 4 & 41.9648505348536 & 0.000000 & Reject H0 \\
\hline Corrected for ties & 4 & 41.9786488265032 & 0.000000 & Reject H0 \\
\hline
\end{tabular}

Table 4: Kruskal-Wallis test results (ethnicity and second-year nursing grades)

\begin{tabular}{|l|c|c|c|c|}
\hline \multicolumn{1}{|c|}{ Method } & $\begin{array}{c}\text { Degree of } \\
\text { Freedom (DF) }\end{array}$ & Chi-square & Probability level & $\begin{array}{c}\text { Decision } \\
(\mathbf{0 . 0 5})\end{array}$ \\
\hline Not corrected for ties & 4 & 41.9648505348536 & 0.000000 & Reject H0 \\
\hline Corrected for ties & 4 & 41.9786488265032 & 0.000000 & Reject H0 \\
\hline
\end{tabular}

\section{Life sciences}

The impact of high school life science grade has revealed varied results in literature. Symes et al. (2005) reported that life science subject is significantly correlated to the performance of nursing student. Similarly, a study conducted by Aldens (2008) revealed that life science subject has a significant impact on the performance of nursing students. In the present study, high school life science grades ranged from 3 to 7 according to Umalusi, with a mode of 5 and a median of 5 . The mean was calculated and found to be $4.9(\mathrm{SD}=0.9)$. A moderately positive significant correlation was found between life science and physical sciences $(0.545 ; p<0.01)$, 
high school mathematics (0.392; $p<0.01)$, admission points (0.613; $p<0.01)$, first-year nursing grade $(0.432 ; p<0.01)$, first-year science grade $(0.513 ; p<0.01)$ second-year science grade (0.418; $p<0.01)$ and second-year nursing grade $(0.335 ; p<0.01)$. However, the results of the stepwise regression excluded this variable from significant predictors of second-year nursing as well as science modules. Although the predictive power of high school life science grade was found to be insignificant for performance of second-year nursing students, this variable may still be found significant in predicting student performance in the NBT grade and general performance of first-year nursing students.

\section{Physical science}

The high school physical science grades ranged from 1 to 7 with a mode of 4 and median of 4 . The mean for high school life science was found to be 3.6 (SD = 1.2). For this variable, data was missing for 70 (31\%) students, probably because this was not one of the subjects they had taken in high school. A moderately positive significant relationship was found between physical science and life science $(0.545 ; p<0.01)$, high school mathematics $(0.392 ; p<0.01)$, admission points (0.609; $p<0.01)$, first-year nursing grade (0.396; $p<0.01$ ), first-year science grade (0.595; $p<0.01)$, second-year nursing grade $(0.370 ; p<0.01)$ and second-year science grade (0.448; $p<0.01)$. In the present study, stepwise regression excluded high school physical science as a significant predictor of academic performance in the second year of the BN programme. Like life science grade, based on the correlation significance with other variables in the study, physical science may still be important in predicting performance of nursing students at other levels of BN programmes.

\section{Life orientation}

The variable of life orientation is less researched as there is no clear evidence indicating the predictive power of this variable and other closely related variables such as social science on the performance of nursing students. Life orientation revealed disappointing correlations among other predictor variables and dependent variables. The grade for this subject ranged between 3 and 7 with a mode of 6 and a median of 6 . The mean score for life orientation subject was of 6 (SD = 0.9). Grades for all $226(100 \%)$ students were obtained. The results of the stepwise regression excluded this variable from significant predictors of second-year nursing as well as science modules. There is therefore no significant relationship between student grade in life orientation and their performance in the second year of the BN programme. 


\section{High school mathematics grade}

Brennan, Best and Small (1996) and Ukpabi (2008) reported that the is a significant $(p<0.01)$ correlation between mathematics and modules prescribed for nursing students. However, in the present study, mathematics was excluded in the stepwise regression, which implies that, for this study, sample mathematics was not a significant predictor of performance in second-year nursing as well as science modules. High school mathematics grades ranged from 3 to 7 with a mode of 3 and the median of 4 . The mean grade for high school mathematics grade was found to be 3.8 ( $\mathrm{SD}=0.9$ ). A moderately positive significant relationship was found between mathematics and physical science (0.355; $p<0.01)$, admission points $(0.638 ; p<0.01)$ NBT 499; $p<0.01)$, first-year nursing grade ( $0.446 ; p<0.01)$, first-year science grade $(0.522 ; p$ $<0.01)$, second-year nursing grade $(0.437 ; p<0.01)$ and second-year science grade $(0.497 ; p$ $<0.01)$. As with life science and physical science grades, the correlations matrix indicates that mathematics may still hold predictive powers in other levels of $\mathrm{BN}$ programmes and therefore the predictive power of high school mathematics must not be underestimated.

\section{Admission points}

University admission points were calculated by grading all grade 12 subjects according to their weight. The admission points of the students ranged between 29 and 58 with a median of 37 and a mode of 36. The mean 'average' was calculated and found to be 37.8 (SD = 5.2). Previous studies analysing the predictive power of students' admission points found mixed results. The literature revealed that students' cumulative grade point average (GPA) was a significant predictor of performance in undergraduate nursing programmes (Campbell and Dickson 1996; Byrd, Garza and Nieswiadomy 1999). However, the recent findings by Alden (2008) reported that cumulative GPA is insignificant in predicting performance and success in nursing programmes. The present study found an insignificant relationship between admission points and performance of second-year nursing students. A moderately positive significant relationship was found between admission points and life science $(0.613 ; p<0.001)$, physical science (0.609; $p<0.001)$, mathematics (0.638; $p<0.001)$, NBT grade $(0.561 ; p<0.001)$, firstyear nursing grade $(0.439 ; p<0.001)$, first-year science grade $(0.397 ; p<0.001)$, second-year nursing grade $(0.437 ; p<0.001)$ and second-year science $(0.428 ; p<0.001)$. Owing to the level of correlation between admission points and both predictor and dependent variables, admission points can still hold significant predictive power for academic performance at other levels of BN programmes. 


\section{EDUCATIONAL IMPLICATIONS}

The following predictor variables have shown a significant $(\mathrm{p}<0.01)$ correlation with secondyear grades in nursing modules: mathematics (0.437), life science (0.335), physical science (0.370) as well as with second-year science modules: life science $(0.418)$ physical science (0.448) and mathematics (0.491).

The predictor variables that demonstrated the strongest predictive power for performance in second-year nursing modules were first-year nursing grade $(\beta=0.394 ; p=0.001)$ and NBT ( $\beta=0.187 ; p<0.10)$ grade. First-year science grade was found to be the strongest predictor ( $p$ $<0.001)$ of performance in both second-year nursing modules $(\beta=0.345)$ as well as in secondyear science modules $(\beta=0.765)$.

The findings of this study have specific implications for higher education institutions in terms of the selection of students into the programme; and how programmes are structured and presented. Lack of progression and throughput of students in academic programmes creates a financial burden on higher education institutions and the students themselves. In addition, the nursing profession, in particular, is challenged by human resource constraints which are perpetuated by programmes which fail to produce competent practitioners after the minimum period of study. It is therefore imperative that academic programme designers ensure that programme entry requirements match the programme expectations and outcomes. School leaving subjects that indicate significant prediction of success in a BN programme should be an entry requirement for the programme. The National Benchmark Test, administered to prospective students, should be aligned to programme entry requirements for a true reflection of the student's fit and readiness for a specific programme. Structured tutoring programmes, which have cost implications for the institution, should be put in place to support students at risk to ensure that they receive appropriate academic support. An added consideration would be the introduction of an extended curriculum programme in line with the National Plan for Higher Education (2001) which widens access to higher education and provides the student with additional time in which to complete the programme and or includes specific academic support for students.

Notwithstanding the fact that the study found these to be non-significant predictors of success, institutions must consider the impact of the non-cognitive predictors of success which have implications for amongst other: the targeted student profile; considerations of student's proficiency in the language of tuition and the values of transcultural engagement in learning. Educators must be equipped to facilitate learning in a culturally diverse group and ensure that students have the best possible student experience. Programme designers must take into 
account, in the design of the curriculum, how success in one subject may impact the success in a related or similar subject pitched at a higher level. This has specific implications for scaffolding of learning and progression rules.

Further research studies should focus on the changing profile of nursing students. In this study, the dependent variable of academic performance was measured by obtaining the average scores obtained in nursing modules as well as in science modules. Using the mean scores for the dependent variable can be statistically viewed as compromising the variability of the dependent variable. Therefore, further investigations should consider separating dependent variables to assess the predictive power of the predictor variables on performance of each and every module offered in the BN programme. Acknowledging that performance, success and throughput as suggested by Jeffreys (2015) is influenced by a wide range of factors, more studies on non-cognitive predictors should be conducted to ensure a more comprehensive understanding of predictors of performance, success and throughput.

\section{STUDY LIMITATIONS}

The study was carried out with only a limited sample from one SoN. The sample of the study included only 226 students, which may limit generalisability of the results beyond the setting. The study included only students with NSC as defined by UMALUSI, the quality assurer for basic education, which therefore implies that all other students who completed their high school outside South Africa and those who completed high school before the year 2008 (when NCS was implemented) were excluded. This criterion may also explain the low SD (1.4) and minimal variations among the participants' age.

\section{CONCLUSION}

This study draws the attention of programme designers to the importance of matching programme entry requirements to programme expectations and outcomes. It also draws the attention of educators to students who may possibly be at risk of unsatisfactory academic performance. It encourages educators to be proactive in implementing support and remedial action as early as possible to ensure that academic performance is not compromised but that nursing students may complete the required programme in minimum time with good academic performance.

\section{NOTE}

1. Statistics South Africa continues to classify people into population groups, since moving away from the past apartheid-based discrimination. This classification uses a population group-based 
classification system that is no longer based on a legal definition, but rather on self-classification (Statistics South Africa 2016).

\section{REFERENCES}

Alden, K. 2008. Predictors of early academic success and program completion among baccalaureate nursing students (Doctoral dissertation). Available from ProQuest Dissertations and Theses database. (UMI No. AAT 3345322).

Barbee, E. L. and S. E. Gibson. 2001. Our dismal progress: The recruitment of non-whites into nursing. The Journal of Nursing Education 40(6): 243-244.

Beeson, Sue Ayers and Grace Kissling. 2001. Predicting success for baccalaureate graduates on the NCLEX-RN. Journal of Professional Nursing 17(3): 121-127.

Biggs, John B. 2011. Teaching for quality learning at university: What the student does. McGraw-Hill Education (UK).

Bovbjerg, R. R., B. A. Ormond and N. Pindus. 2009. The nursing workforce challenge: Public policy for a dynamic and complex market. Washington, DC: The Urban Institute.

Brennan, A. L., D. G. Best and S. P. Small. 1996. Tracking student progress in a baccalaureate nursing program: Academic indicators. The Canadian Journal of Nursing Research $=$ Revue Canadienne De Recherche En Sciences Infirmieres 28(2) (Summer): 85-97.

Byrd, Gloria, Chris Garza, and Rose Nieswiadomy. 1999. Predictors of successful completion of a baccalaureate nursing program. Nurse Educator 24(6): 33-37.

Callister, L. C., G. Matsumura, S. Lookinland, S. Mangum and C. Loucks. 2005. Inquiry in baccalaureate nursing education: Fostering evidence-based practice. The Journal of Nursing Education 44(2): 59-64.

Cercone, Kathleen. 2008. Characteristics of adult learners with implications for online learning design. AACE Journal 16(2): 137-159.

Campbell, Arthur Ree and Charlie J. Dickson. 1996. Predicting student success: A 10-year review using integrative review and meta-analysis. Journal of Professional Nursing 12(1): 47-59.

Chaiklin, Seth. 2003. The zone of proximal development in Vygotsky's analysis of learning and instruction. Vygotsky's Educational Theory in Cultural Context 1: 39-64.

Chisholm, Linda and Haroon Bhorat. 2004. Changing class: Education and social change in postapartheid South Africa. Zed Books London.

Crain, William. 2015. Theories of development: Concepts and applications. Psychology Press.

Dyck, Jeff M., John Oliffe, Alison Phinney and Bernie Garrett. 2009. Nursing instructors' and male nursing students' perceptions of undergraduate, classroom nursing education. Nurse Education Today 29(6): 649-653.

Ehrenreich, Barbara and Deirdre English. 2010. Witches, midwives, and nurses: A history of women healers. Feminist Press at CUNY.

El Ansari, Walid. 2002. Student nurse satisfaction levels with their courses: Part I - effects of demographic variables. Nurse Education Today 22(2): 159-170.

Gardner, J. D. 2005. A successful minority retention project. The Journal of Nursing Education 44(12): 566-568.

Goddard, Maria, Russell Mannion and Peter Smith. 2004. Enhancing performance in health care: A theoretical perspective on agency and the role of information. Studying the Organisation and Delivery of Health Services: A Reader 9: 199.

Gravett, Sarah. 2005. Adult learning: Designing and implementing learning events: A dialogic approach. Van Schaik.

Griesel, Hanlie. 2006. Access and entry level benchmarks: The national benchmark tests project. Higher 
Education South Africa.

Harvey, Arlene and Patty Kamvounias. 2008. Bridging the implementation gap: A teacher-as- learner approach to teaching and learning policy. Higher Education Research \& Development 27(1): 3141.

Higgins, Bonnie. 2005. Strategies for lowering attrition rates and raising NCLEX-RN® pass rates. Journal of Nursing Education 44(12): 541.

Hopkins, T. H. 2008. Early identification of at-risk nursing students: A student support model. The Journal of Nursing Education 47(6): 254-259.

Jarvis, Peter. 2012. Towards a comprehensive theory of human learning. Vol. 1. Routledge.

Jeffreys, Marianne R. 1998. Predicting nontraditional student retention and academic achievement. Nurse Educator 23(1): 42-48.

Jeffreys, Marianne R. 2002. Students' perceptions of variables influencing retention: A pretest and posttest approach. Nurse Educator 27(1): 16-19.

Jeffreys, M. R. 2007. Nontraditional students' perceptions of variables influencing retention: A multisite study. Nurse Educator 32(4): 161-167.

Jeffreys, Marianne R. 2013. Jeffreys's Nursing Universal Retention and Success (NURS) model. Unpublished Model, adapted from Jeffreys, M. R. 2012. Nursing student retention: Understanding the process and making a difference: 12 .

Jeffreys, Marianne R. 2015. Jeffreys’s nursing universal retention and success model: Overview and action ideas for optimizing outcomes A-Z. Nurse Education Today 35(3): 425-431.

Knowles, Malcolm S. 1970. The modern practice of adult education. Vol. 41. New York Association Press New York.

Lewis, C. and J. H. Lewis. 2000. Predicting academic success of transfer nursing students. The Journal of Nursing Education 39(5): 234-236.

Manifold, Carol and R. N. Betty Rambur DNSc. 2001. Predictors of attrition in American Indian nursing students. Journal of Nursing Education 40(6): 279.

Meadus, R. J. and J. C. Twomey. 2007. Men in nursing: Making the right choice. The Canadian Nurse 103(2): 13-16.

McLaughlin, Katrina, Orla T. Muldoon and Marianne Moutray. 2010. Gender, gender roles and completion of nursing education: A longitudinal study. Nurse Education Today 30(4): 303-307.

Meyer, S. M. and S. E. van Niekerk. 2008. Professional nurse educator in practice. Juta and Company Ltd.

Mouton, N., G. P. Louw and G. L. Strydom. 2012. Restructuring and mergers of the South African postapartheid tertiary system (1994-2011): A critical analysis. Article submitted to the International Business and Economic Research Journal.

National Plan for Higher Education. 2001. Ministry of Education, Pretoria, February.

Newton, Sarah E., Laureen H. Smith, Gary Moore and Morris Magnan. 2007. Predicting early academic achievement in a baccalaureate nursing program. Journal of Professional Nursing 23(3): 144-149.

NSC pass requirements. 2013. A discussion document for Umalusi on the NSC pass mark. http://www.umalusi.org.za/ (Accessed January 2015).

Potolsky, Alicia, Jayne Cohen and Coleen Saylor. 2003. Academic performance of nursing students: Do prerequisite grades and tutoring make a difference? Nursing Education Perspectives 24(5): 246250.

Rule, Rebecca A. 2004. The use of discriminant function analysis to predict student success on the NCLEX-RN. Journal of Nursing Education 43(10): 440.

Salamonson, Yenna and Sharon Andrew. 2006. Academic performance in nursing students: Influence of part-time employment, age and ethnicity. Journal of Advanced Nursing 55(3): 342-349. 
Shelton, Elisabeth N. 2003. Faculty support and student retention. Journal of Nursing Education 42(2): 68-75.

Shukla, Akhilesh and Dhananjai Yadav. 2011. A critical appraisal of constructivist approach of teaching. TechnoLEARN: An International Journal of Educational Technology 1(2): 197-203.

Simmons, L. E., G. Haupt and L. Davis. 2004. The usefulness of the nurse entrance test (NET) for prediction of successful completion in a nursing program. Net Technical and Development Report, 45-48. Educational Resources Inc., Publishers.

Statistics South Africa. 2016. Community Survey 2016. Statistical release P0301. http://cs2016. statssa.gov.za/wp-content/uploads/2016/07/NT-30-06-2016-RELEASE-for-CS-2016-_Statistical -releas_1-July-2016.pdf

Steele, Rebekah, William Lauder, Cristina Caperchione and Jenny Anastasi. 2005. An exploratory study of the concerns of mature access to nursing students and the coping strategies used to manage these adverse experiences. Nurse Education Today 25(7): 573-581.

Symes, Lene, Kathryn Tart and Lucille Travis. 2005. An evaluation of the nursing success program: Reading comprehension, graduation rates, and diversity. Nurse Educator 30(5): 217-220.

Ukpabi, Chinasa Victor. 2008. Predictors of successful nursing education outcomes: A study of the North Carolina Central University's nursing program. Educational Research Quarterly 32(2): 30.

Vygotsky, Lev. 1978. Interaction between learning and development. Readings on the Development of Children 23(3): 34-41.

Wise, R. E. M. 2009. The socialization of men to the nursing profession: A symbolic interactionist approach. Ph.D. Thesis. Pennsylvania: The Pennsylvania State University.

Wong, Julia and Shirley Wong. 1999. Contribution of basic sciences to academic success in nursing education. International Journal of Nursing Studies 36(4): 3. 